\title{
The Effects of Tasks on the Learning of Lexical Bundles by Chinese EFL Learners
}

\author{
Zhongqin Cao \\ School of Foreign Languages Teaching, Guangdong Pharmaceutical University, Guangzhou, China
}

\begin{abstract}
This study investigated the effects of task-induced involvement load on the learning of lexical bundles. One of the three tasks with varying involvement load was assigned to 70 non-English major students. The three tasks were reading comprehension, reading comprehension plus gap-filling, and sentence writing. Upon completion of the tasks, the students were given an immediate posttest. One week later, the students were given the same test. Sentence writing group significantly outperformed the other two groups on both immediate and delayed posttests. A one-way ANOVA was performed to analyze the relationship between the learning of lexical bundles and various involvement loads. The results of the study showed that task has an impact on the learning of lexical bundles, which supported the involvement load hypothesis that higher involvement induced by the task was more beneficial to the learning of lexical bundles.
\end{abstract}

Index Terms — involvement load, lexical bundle, reading, task

\section{INTRODUCTION}

It is widely acknowledged that vocabulary is an indispensable foundation for language learning. Learning vocabulary is not just acquiring individual words, but phraseology. Lexical bundles, as an important constituent of language, play a vital part in language learning. A learner's language competence is closely related to the accumulation of lexical bundles. Lexical bundles are becoming an increasingly important topic in second language acquisition. Various terminologies, such as chunks, formulaic sequences, multiword units, prefabricated expressions, formulaic speech, and routinized expressions were used to express lexical bundles. Lexical bundles may not only provide language learners with more than a convenient way to communicate but also facilitate further language learning (Norbert Schmitt and Ronald Carter, 2004).

\section{LITERATURE REVIEW}

The Involvement Load Hypothesis was put forward by Laufer and Hulstijn in 2001, which assumed that vocabulary acquisition is conditional upon the degree of involvement in processing these words. The construct of involvement is composed of three components: need, search, and evaluation.

"The need is the motivational, noncognitive dimension of involvement. Need is moderate when it is externally imposed (e.g., when the teacher asks the learner to fill in the gap in a sentence with previously unknown words) and the need is strong when it is self-imposed (e.g., when the learner decides to look up a word when writing a sentence)" (Hulstijn and Laufer, 2001, p.543).

"Search is the attempt to find the meaning of an unknown L2 word from expressing a concept by consulting a dictionary or another authority. Evaluation is a comparison of a given word with other words, a specific meaning of a word with its other meanings, or combining the word with other words in order to assess whether a word does or does not fit its context" (Hulstijn and Laufer, 2001, p.543-544).

Involvement is operationalised by designing tasks with varying degrees of need, search, and evaluation. Many empirical studies have demonstrated the influence of involvement load on language acquisition. Numerous studies have shown that incidental vocabulary learning can be enhanced from reading (Mason \& Krashen, 1997; Dupuy \& Krashen, 1993; Nagy, Anderson \& Herman, 1987; Nagy, Herman \& Anderson, 1985).

Many researchers have examined the relationship between tasks and their effects on incidental vocabulary learning in recent years. Their studies have revealed how incidental vocabulary learning is enhanced through text-based tasks. Hulstijn and Laufer (2001) conducted two parallel experiments on learners of English to investigate the effects of task-induced involvement on the initial learning and retention of 10 vocabulary words in two countries. Three tasks with different levels of involvement were assigned: reading comprehension with marginal glosses, reading comprehension plus gap-fill, and writing a composition with the target words. Short-term retention and long-term retention of the words were measured by providing the L1 translation or English explanations for 10 target words. As predicted, the retention of the word was correlated with the amount of the involvement.

Gai Shuhua (2003) investigated the incidental vocabulary acquisition of English majors in reading. The results of her study showed different tasks had different effects on vocabulary acquisition and students' vocabulary size also had impact on the acquisition as well. 
In the study of Duan Shiping and Yan Chensong (2004), three tasks with varying involvement load were administered to three parallel classes. The three tasks were reading a passage with multiple word annotations, one word annotation, and no annotation. The results revealed that both the multiple word annotations and the one word annotation facilitated incidental vocabulary learning, but students benefited more in vocabulary learning from the multiple word annotations than the one word annotation.

Keith S. Folse's study (2006) used a within-subjects design to test the impact of the type of written exercise on L2 vocabulary learning. The participants practiced target vocabulary in three types of written exercises: one fill-in-the-blank exercise, three fill-in-the-blank exercises, and one original-sentence-writing exercise. An unannounced posttest tested the meaning of the word (L1 translation or L2 synonym) and usage of the word in a student-written sentence. The findings indicated that the important feature of a given L2 vocabulary exercise is number of word retrievals required, but not depth of word processing.

Kim (2008) conducted two empirical experiments to examine the Involvement Load Hypothesis in vocabulary learning. Experiment 1 was to investigate how tasks with different involvement loads influenced the by L2 learners' learning and retention of target words. The results showed that the higher involvement induced by the task resulted in better initial vocabulary learning and retention. Experiment 2 tried to test whether two tasks claiming to have the same involvement load would produce the same effect in initial learning and retention of target words. The results of Experiment 2 showed that different tasks with the same involvement load would result in equivalent amounts of initial learning and retention of new words.

In the study of Jing \& Jianbin (2009), they assigned two listening comprehension passages with different involvement indexes to three classes of non-English major students. Both immediate and delayed tests showed that there was a significant difference among the three different tasks and confirmed that tasks with higher involvement load resulted in higher retention.

Nassaji, Hossein and $\mathrm{Hu}$, Hsueh-chao Marcella (2012) investigated the relationship between task-induced involvement load and ESL learners' inferring and learning word meanings from context. Thirty-two ESL learners were randomly divided into three groups, with each group receiving a different version of a text which differs in terms of the level of involvement load. The results showed a significant correlation between level of involvement load, learners' use of lexical inferring strategies, and subsequent retention of successfully inferred words.

Gregory D. Keating's study (2008) tests whether vocabulary learning and retention in a second language are contingent upon a task's involvement load. Three vocabulary learning tasks with different involvement load: reading comprehension, reading comprehension plus fill in, and sentence writing were administered to beginning learners of Spanish. Passive and active recall posttests were given immediately after treatment and two weeks later. The results were consonant with the predictions of the Involvement Load Hypothesis.

Zabih O. Javanbakht (2011) investigated the impacts of three tasks: reading comprehension, reading comprehension with fill-in gaps, and sentence writing, on incidental vocabulary learning. The tasks were assigned to three groups of male Iranian elementary EFL learners. After the completion of each task, two unannounced tests were given to measure short term and long term retention of the words. The results showed evidence of significant impact of task involvement on incidental vocabulary learning.

The studies reviewed above supported Involvement Load Hypothesis and provided evidence for the task effects on incidental vocabulary learning.

Compared with the abundant research done on task effects and single word learning, the amount of research into the relationship between task types and lexical bundles is not much.

Researches that have been reviewed above tests the involvement load hypothesis to some extent though, these experiments only have tested its effects on single words. Few studies that compare the effects of various involvement loads on the learning of lexical bundles have been done. In order to test the effects of tasks with varying involvement loads on lexical bundles, the present study was conducted.

\section{METHOD}

The current study sought to address the following research question:

How do tasks with varying involvement loads influence learners' initial learning and retention of lexical bundles?

\section{A. Participants}

The participants of the study (70) were non-English major students in their second year of college. The participants were all native speakers of Chinese learning English as a foreign language, aged between 18 and 20. They took English as a compulsory course. They were randomly assigned to three groups with different tasks.

\section{B. $\quad$ Target Lexical Bundles}

Altogether 10 target lexical bundles were selected for investigation. Students with higher English proficiency but did not take part in the experiment were asked to recognize lexical bundles from a list of 10 bundles picked out from the reading material. Most of bundles were unfamiliar to them. As I mentioned earlier, the proficiency of these students was higher than that of the experimental students, so these bundles were selected as target bundles. 


\section{Tasks}

In this study, three tasks with varying involvement loads were used to explore their impacts on the learning and retention of lexical bundles. The tasks were adapted from Hulstijn \& Laufer (2001) and Zabih O, Javanbakht (2011).

Task One: reading comprehension. The students assigned to this task (Group 1) were assigned a passage and five comprehension questions. The passage and the questions were taken from the internet. The students were required to read the passage and answer the comprehension questions. The 10 target bundles were underlined and their Chinese meanings were listed at the bottom of each page. So, in terms of involvement load, this task induced moderate need, but no search and evaluation were present. It indicated its involvement index was 1 (Hulstijn \& Laufer, 2001).

Task Two: reading comprehension plus gap-filling. The students assigned to this task (Group 2) were presented with the same passage and comprehension questions as those in task one. The difference between task two and task one was that the 10 underlined target bundles were deleted and therefore having 10 gaps. Five additional bundles worked as distracters and the 10 target bundles were listed randomly for the students to choose from to fill in the gaps on a separate paper. Each of the ten bundles was followed by its Chinese meaning at the bottom of each page. The involvement index of this task was 2 . The task induced moderate need but no search. It induced moderate evaluation because it provided the context (Hulstijn \& Laufer, 2001).

Task Three: sentence writing. The students allocated to this task (Group 3) were presented with the passage to read and the same ten target bundles were underlined. They were required to write a complete and meaningful sentence for each bundle. In terms of involvement load, this task induced a strong evaluation, moderate need and no search, so its involvement index was 3 (Hulstijn \& Laufer, 2001).

\section{Tests}

Two unannounced posttests were conducted to evaluate the initial learning and retention of the target bundles: an immediate posttest (immediately after the completing of the tasks) and a delayed posttest (one week after the completion of the tasks). In both posttests, the students were presented with the 10 target bundles to give their Chinese translations to evaluate their knowledge of the bundles. The tests were scored by the researcher. The scoring procedure was adopted from Hulstijn \& Laufer (2001), in which not translated or wrongly translated bundle got zero, a correct translation obtained 1 point and partially correct translation obtained half a point.

\section{E. Procedure}

The experiment was performed on 2 separate days over 1 week. The three groups of students were given a worksheet with one of the three different tasks mentioned above. The time on task was not controlled, which indicated that the students spent however much time they needed to complete the tasks. Once tasks were completed, the worksheets were gathered. Afterwards, the students were assigned an immediate unannounced posttest. They were required to give the L1 translations or English explanations of the given bundles. A week later, the students were given the same unannounced test.

\section{RESULTS}

The research question examined how tasks with varying involvement loads influence students' initial learning and retention of lexical bundles. In order to address it, the scores the students gained in the three tasks (reading comprehension, reading comprehension plus gap-filling, and sentence writing) were compared.

The scoring method of the tests was in line with Laufer and Hulstijn's (2001). Not or wrongly translated was scored zero; relative but not exact translation was scored 0.5 point; exact translation was given 1 point. Date collected from the two posttests was analyzed using SPSS17.0. The descriptive statistics of the scores on the immediate and delayed tests of the target bundles were displayed in Table 1.

TABLE I.

DESCRIPTIVE STATISTICS OF PERFORMANCE ON IMMEDIATE AND DELAYED POSTTESTS

\begin{tabular}{|l|l|l|l|l|l|}
\hline \multirow{2}{*}{ Groups } & \multirow{2}{*}{$\mathrm{N}$} & \multicolumn{3}{|l|}{ Immediate Posttest } & Delayed Posttest \\
\cline { 3 - 6 } & & Mean & SD & Mean & SD \\
\hline Group 1 & 22 & 6.1364 & 1.77403 & 4.4318 & 2.30577 \\
\hline Group 2 & 24 & 8.2917 & 1.73779 & 4.5000 & 2.57918 \\
\hline Group 3 & 24 & 9.5625 & 0.99250 & 6.3542 & 2.00260 \\
\hline Total & 70 & 8.0500 & 2.06796 & 5.1143 & 2.44678 \\
\hline
\end{tabular}

Note. Group 1 = Reading comprehension group; Group 2 = Reading comprehension plus gap-filling group; Group $3=$ Sentence writing group.

As shown in Table 1, the descriptive statistics showed that the mean scores of the three groups differ significantly from each other, with Group $3(\mathrm{M}=9.5625, \mathrm{SD}=0.99250)$ acquiring the highest mean score, followed by the Group 2 $(\mathrm{M}=8.2917, \mathrm{SD}=1.73779)$ and Group $1(\mathrm{M}=6.1364, \mathrm{SD}=1.77403)$ on immediate posttest. On delayed posttest, Group $3(\mathrm{M}=6.3542, \mathrm{SD}=2.00260)$ also performed better than Group $1(\mathrm{M}=4.4318, \mathrm{SD}=2.30577)$ and $\mathrm{Group} 2(\mathrm{M}$ $=4.5000, \mathrm{SD}=2.57918)$. In addition, for all the three groups, there was a decline of the mean scores in delayed posttest compared with that of immediate posttest.

To figure out the statistical difference in the mean scores of immediate and delayed posttests among the three groups, 
a one-way ANOVA was performed.

TABLE II

ANOVA FOR IMMEDIATE AND DELAYED POSTTEST SCORES

\begin{tabular}{|l|l|l|l|l|l|l|}
\hline Test & & Sum of Squares & df & Mean Square & F & Sig. \\
\hline \multirow{2}{*}{$\begin{array}{l}\text { Immediate } \\
\text { posttest }\end{array}$} & Between Groups & 136.870 & 2 & 68.435 & 28.982 & 0.000 \\
\cline { 2 - 5 } & Within Groups & 158.205 & 67 & 2.361 & & \\
\cline { 2 - 5 } & Total & 295.075 & 69 & & 5.275 & 0.007 \\
\hline \multirow{2}{*}{$\begin{array}{l}\text { Delayed } \\
\text { posttest }\end{array}$} & Between Groups & 56.198 & 2 & 28.099 & & \\
\cline { 2 - 5 } & Within Groups & 356.887 & 6.327 & 69 & & \\
\cline { 2 - 5 } & Total & 413.086 & 6.07 & \\
\hline
\end{tabular}

As reflected in Table 2, the results of the ANOVA revealed a statistically significant difference in the immediate posttest among the three groups, $\mathrm{F}(2,67)=28.982, \mathrm{p}=.000<.001$. The results also showed that there was a significant difference in the delayed posttests, $\mathrm{F}(2,67)=5.275, \mathrm{p}=.007<.05$.

As the F value was significant, Scheffé post hoc tests were conducted for the two posttests to locate the differences. From the results demonstrated in Table 3, we can see that there was a significant difference among Group 1, Group 2 and Group 3 in the immediate posttest $(\mathrm{p}=.000<.05, \mathrm{p}=.000<.05$ and $\mathrm{p}=.021<.05$ respectively). While Scheffé post hoc tests for delayed posttest only showed significant difference between Group 1 and Group $3(\mathrm{p}=.023<.05)$ and between Group 2 and Group $3(\mathrm{p}=.026<.05)$. No difference was revealed between Group 1 and Group 2 ( $\mathrm{p}=.995$ $>.05)$.

TABLE III.

SCHEFFÉ Post Hoc MultiPle RANGe TEST FOR IMMEDIATE AND DELAYEd POSTTESTS

\begin{tabular}{|c|c|c|c|c|c|c|c|}
\hline \multirow[t]{2}{*}{ Test } & \multirow[t]{2}{*}{ (I) Groups } & \multirow[t]{2}{*}{ (J) Groups } & \multirow{2}{*}{$\begin{array}{l}\text { Mean } \\
\text { Difference (I-J) }\end{array}$} & \multirow[t]{2}{*}{ Std. Error } & \multirow[t]{2}{*}{ Sig. } & \multicolumn{2}{|c|}{ 95\% Confidence Interval } \\
\hline & & & & & & Lower Bound & Upper Bound \\
\hline \multirow{5}{*}{$\begin{array}{l}\text { Immediate } \\
\text { posttest }\end{array}$} & Group 1 & Group 2 & $-2.15530 *$ & .45356 & .000 & -3.2908 & -1.0198 \\
\hline & & Group 3 & $-3.42614 *$ & .45356 & .000 & -4.5616 & -2.2906 \\
\hline & Group 2 & $\begin{array}{l}\text { Group } 1 \\
\text { Group } 3\end{array}$ & $\begin{array}{r}2.15530^{*} \\
-1.27083^{*}\end{array}$ & $\begin{array}{l}.45356 \\
.44359\end{array}$ & $\begin{array}{l}.000 \\
.021\end{array}$ & $\begin{array}{l}1.0198 \\
-2.3814\end{array}$ & $\begin{array}{l}3.2908 \\
-.1603\end{array}$ \\
\hline & Group 3 & Group 1 & $3.42614 *$ & .45356 & .000 & 2.2906 & 4.5616 \\
\hline & & Group 2 & $1.27083^{*}$ & .44359 & .021 & .1603 & 2.3814 \\
\hline \multirow{6}{*}{$\begin{array}{l}\text { Delayed } \\
\text { posttest }\end{array}$} & Group 1 & Group 2 & -.06818 & .68122 & .995 & -1.7736 & 1.6373 \\
\hline & & Group 3 & $-1.92235^{*}$ & .68122 & .023 & -3.6278 & -.2169 \\
\hline & Group 2 & Group 1 & -.06818 & .68122 & .995 & -1.6373 & 1.7736 \\
\hline & & Group 3 & $-1.85417 *$ & .66625 & .026 & -3.5221 & -.1862 \\
\hline & Group 3 & Group 1 & $1.92235^{*}$ & .68122 & .023 & .2169 & 3.6278 \\
\hline & & Group 2 & $1.85417 *$ & .66625 & .026 & .1862 & 3.5221 \\
\hline
\end{tabular}

*The mean difference is significant at the 0.05 level.

\section{Discussion}

The results of immediate posttest strongly supported the Involvement Load hypothesis that greater involvement in processing resulted in better effects on initial learning of lexical bundles. Of the three tasks, the sentence writing was the most effective in vocabulary learning, followed by reading comprehension plus gap-filling and reading comprehension tasks. While in the delayed posttest, Group 3 also produced the highest scores. This might result from the fact that sentence writing task which demands deeper cognitive effort contributed more to retention than noticing the glossary, answering comprehension questions and fill in the gaps. Compared with immediate posttest, the scores of delayed posttest showed decline in all the three groups. The decline might arise from the one-week interval between the two posttests, and that the students participating in the study were not exposed to the ten target bundles between the test interval. Therefore, another factor--multiple exposures, which might facilitate the retention of lexical bundles, was worth considering.

As was shown by the experiment, the task of sentence writing produced best initial learning and retention, followed by the tasks of reading comprehension plus gap-filling and reading comprehension. In the current study, each task was significantly different from the other two tasks in initial learning. Students in Group 3 gained the highest scores in both tests which showed that, among the three tasks, the sentence writing task was most beneficial in initial learning and retention of lexical bundles.

A one-way ANOVA was performed to find out the relationship between the learning of lexical bundles and task involvement load. ANOVA for immediate posttest scores showed that, with $\mathrm{F}(2,67)=28.892, \mathrm{p}=.000$, there were significant differences in the mean scores among the three groups. Similarly, ANOVA for delayed posttest scores showed, with $\mathrm{F}(2,67)=5.275, \mathrm{p}=.007$, significant differences among the three groups. The results implied that the degree of involvement load did have influence on the learning and retention of the lexical bundles.

Scheffé post hoc tests were conducted for the purpose of locating the differences. The results revealed significant differences among the three groups in the immediate posttest. While Scheffé post hoc tests for delayed posttest only showed significant difference between Group 1 and Group $3(\mathrm{p}=.023<.05$ ) ) and between Group 2 and Group 3 (p 
$=.026<.05$.). No difference was revealed between Group 1 and Group 2. Though the mean score of Group 2 was higher than that of Group 1 in delayed posttest, they did not show significant difference. This may be due to the fact that although the task of reading comprehension plus gap-filling demanded moderate evaluation in completing the task compared with reading comprehension task, the involvement was not high enough to guarantee acquisition of lexical bundles.

Finally, based on the results of the present study, it can be concluded that students benefit more from sentence writing task which demands deeper cognitive effort than reading comprehension and reading comprehension plus gap-filling in the acquisition of lexical bundles.

\section{CONCLUSIONS}

The present study was designed to examine the relationship between tasks with varying involvement loads on learners learning of lexical bundles. Its aim was to find out how different involvement loads influence learning and retention of lexical bundles. The results of this study support the evidence of L2 vocabulary learning as a result of task-induced involvement. The findings were partially in accordance with those of Hulstijn and Laufer's (2001), which showed that the task with a higher involvement elicited more effective words learning and retention. In addition, the current study provided 1 evidence for acquisition of lexical bundles. As to the learning and retention of lexical bundles, output task (sentence writing task) was more effective than input tasks (reading comprehension and reading comprehension plus gap-filling tasks).

Therefore, it was concluded that the results of this research on learning of lexical bundles provided support for the involvement load hypothesis in second language vocabulary learning and proved that Involvement Load Hypothesis is applicable to the acquisition of lexical bundles. To conclude, the addressing of the research question would facilitate further understanding of involvement load.

\section{LIMITATIONS AND IMPLICATIONS}

Based on the findings of the current study, L2 pedagogical implications can be drawn. Teachers should consider designing tasks with various involvement loads for different bundles to enhance the acquisition. As mentioned above, tasks with higher involvements were more beneficial for initial learning and retention of lexical bundles than those with lower involvements. The results of the current study provide L2 teachers with a theoretical basis, especially in the teaching of lexical bundles.

The students in this study participated in each task only once. Therefore, in order to gain full understanding of effectiveness of each task on vocabulary learning, multiple tasks should be administered to the students.

\section{REFERENCES}

[1] Duan, Shiping, \& Yan, Chensong. (2004). The effects of multiple annotations on incidental vocabulary acquisition. Foreign Language Teaching and Research (bimonthly), 36, 213-218.

[2] Dupuy, B., \& Krashen, S. (1993). Incidental vocabulary acquisition in French as a foreign language. Applied Language Learning, 4, 55-63.

[3] Folse, K. S. (2006). The Effect of Type of Written Exercise on L2 Vocabulary Retention TESOL Quarterly, 40(2), $273-293$.

[4] Gai, Shuhua. (2003). Empirical study on incidental vocabulary acquisition of English majors. Foreign Language Teaching and Research (bimonthly), 35, 282-286.

[5] Hulstijn, J. H., \& Laufer, B. (2001). Some empirical evidence for the involvement load hypothesis in vocabulary acquisition. Language Learning, 51, 539-558.

[6] Javanbakht, Z. O. (2011). The Impact of Tasks on Male Iranian Elementary EFL Learners Incidental Vocabulary Learning. Language Education in Asia, 2(1), 28-42.

[7] Keating, G. D. (2008). Task effectiveness and word learning in a second language: The involvement load hypothesis on trial. Language Teaching Research, 12(3), 365-386.

[8] Kim, Y. (2008). The role of task induced involvement and learner proficiency in L2 vocabulary acquisition. Language Learning, $58(2), 285-325$.

[9] Laufer, B., \& Hulstijn, J. (2001). Incidental vocabulary acquisition in a second language: The construct of task-induced involvement. Applied Linguistics, 22(1), 1-26.

[10] Lu, J., \& Huang, J. (2009). An empirical study of the involvement load hypothesis in incidental vocabulary acquisition in EFL listening. Polyglossia, 16, 1-11.

[11] Mason, B., \& Krashen, S. (1997). Extensive reading in English as a foreign Language. System, 25, 9-102.

[12] Nagy, W. E., Herman, P. A., \& R. C. Anderson. (1985). Learning words from context. Reading Research Quarterly, 20, 233-253.

[13] Nagy, W. E., Anderson, R. C., \& Herman, P. A. (1987). Learning word meanings from con text during normal reading. American Educational Research Journal, 24, 237-270.

[14] Nassaji, Hossein, \& Hu, Hsueh-chao Marcella. (2012). The relationship between task-induced involvement load and learning new words from context. International Review of Applied Linguistics in Language Teaching, 50(1), 69-86.

[15] Schmidt, R. (1994). Implicit learning and the cognitive unconscious: Of artificial grammars and the SLA. In N. C. Ellis (ED.), Implicit and explicit learning of languages (pp.165-210). London: Academic Press. 
Zhongqin Cao was born in Tangshan, China on April 30, 1975. She got his M.A. in linguistics from Xi'an Jiaotsong University, China in 2003.

She is currently a lecturer in School of Foreign Languages Teaching, Guangdong Pharmaceutical University, Guangzhou, China. Her research interests include corpus linguistics and second lexical chunks. 